\title{
Medical Image of the Week: A Positive Methacholine Challenge
}

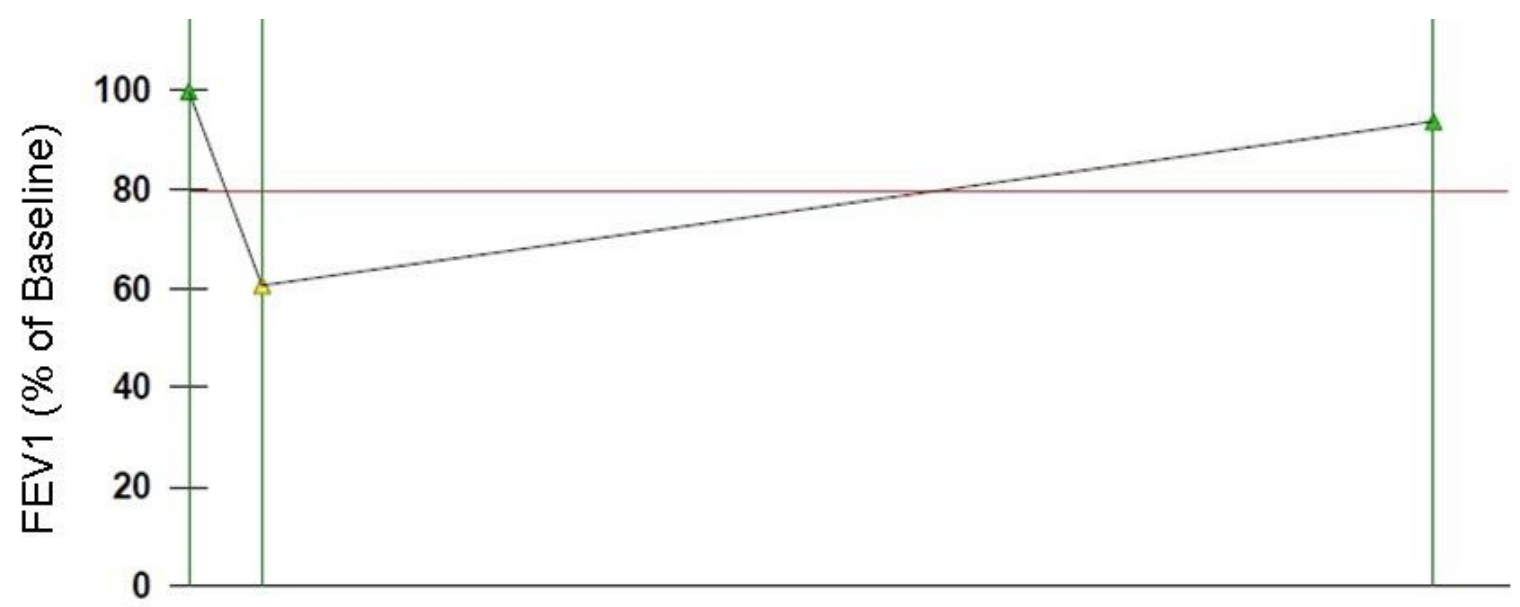

Methacholine

Conc $(\mathrm{mg} / \mathrm{dL}) \quad 0 \quad 0.06$

Post BD

FEV1 (L) $\quad 3.942 .39$

Figure 1. Positive methacholine challenge. The patient had a 39\% drop in FEV1 after inhalation of $0.0625 \mathrm{mg} / \mathrm{dL}$ of methacholine, the lowest concentration tested. The drop in FEV1 was reversed by a bronchodilator (Post BD).

A methacholine challenge test is one of the methods to assess bronchial hyperresponsiveness (BHR). BHR is one of the features that can contribute to the diagnosis of asthma. The test is reported as a PC-20 value; the inhaled provocative concentration causing a $20 \%$ drop or more in the pretest FEV1. This patient had a PC20 of $<0.1 \mathrm{mg} / \mathrm{mL}$ which is interpreted as a moderate to severe bronchial hyperresponsiveness by ATS guidelines (1). A normal bronchial response is a PC-20 > $16 \mathrm{mg} / \mathrm{ml}, 4-16 \mathrm{mg} / \mathrm{mL}$ is considered borderline and $1-4 \mathrm{mg} / \mathrm{mL}$ is mild BHR according to the ATS guidelines.

Mohammad Dalabih, MBBS and Linda Snyder, MD

University of Arizona

Tucson, AZ USA

\section{Reference}

1. Crapo RO, Casaburi R, Coates AL, Enright PL, Hankinson JL, Irvin CG, Macintyre NR, McKay RT, Wanger JS, Anderson SD, Cockcroft DW, Fish JE, Sterk PJ. Guidelines for methacholine and exercise challenge testing-1999. Am J Respir Crit Care Med. 2000 Jan;161(1):309-29. 